\title{
Терентьев В. И.
}

\section{«НУТАГ» КАК ПОНИМАНИЕ ОБРАЗА МАЛОЙ РОДИНЫ У СОВРЕМЕННЫХ МОНГОЛОВ}

\begin{abstract}
Исследуется одна из ключевых составляющих этничности современных монголов - представление о родных кочевьях. Приводятся различные варианты интерпретации данного образа и анализируется ситуативный характер его восприятия. При рассмотрении источников особое внимание уделяется литературному и музыкально-поэтическому творчеству монгольских авторов XX - нач. XXI в. В заключение подчеркивается двойственная сущность современных представлений о малой родине монголов: внешняя абстрактность и внутренняя индивидуальная образность и ассоциативность с конкретной местностью, природными объектами и духами-хозяевами родного пространства.
\end{abstract}

Ключевые слова: Монголия, монголы, этническое самосознание, этничность, родина, образ.

Для каждого человека понятие «Родина» имеет сакральное значение, в особенности для тех, кто находится вне места своего рождения, в частности за границей. Это ярко наблюдается на примере моих соотечественников, продолжительно проживающих в Монголии, но не относящихся к категории здесь родившихся ${ }^{1}$ (дипломаты, учителя, бизнесмены). В разговорах между нами периодически возникают вопросы, связанные с локализацией родного места. В процессе ответов происходит ментальное разграничение по близости населенных пунктов (Москва, Урал, Сибирь и т.д.). Если же собеседники русские по самосознанию, но являются гражданами одной из бывших советских республик (преимущественно - Республика Беларусь и Украина), то свою родину они могут часто соотнести с Советским Союзом. И это уже есть не пространственная, но временная проекция самосознания.

Для людей важно ощущение опоры, стержня самоидентификации, коим выступает образ или представление о родине, а для проживающих за границей постепенная ностальгизация образа родины (или малой родины) еще более ценна. Этот образ несет в себе ассоциации с личной историей, семьей, родными, живыми и умершими, с местами упокоения последних. Относительная статичность российской культуры именно в контексте восприятия дистанции между родиной и своим текущим, актуальным местонахождением отличается от динамики монгольского кочевого восприятия образа родины. Пожалуй, это есть важная причина специфики монгольского варианта малой родины, изучению которого и посвящена данная статья. Представление о нутаге является одним из важных компонентов, формирующих этничность современных монголов.

Слово «нутаг» в первом значении переводится с монгольского языка как «родное место; родные кочевья; родина», во втором - «территория; область; регион, зона», в третьем - «местность, ландшафт» (БАМРС. Т. 2: 428). В нашем повествовании чаще всего будет использоваться словосочетание «родные кочевья», как максимально выражающее смысл и ассоциации, вкладываемые каждым монголом в понимание родины. Слово «кочевья» отражает все возможные коннотации, связанные с обжитым профанно-сакральным пространством микрокосма, включающего юрту как axis mundi (лат. «ось мира») личной вселенной каждого монгола и

\footnotetext{
1 Таковыми являются «местные русские», их представления о родине - это тема отдельного повествования. Тем не менее, интересно, что многие из них вполне отчетливо идентифицируют Монголию как свою родину и не воспринимают Россию таковой. Некоторые даже после посещения страны более явственно понимают свою инаковость, отторгают себя от россиян или, правильнее сказать, наоборот, еще дальше дистанцируют от себя русских России и, соответственно, неместных русских, т.е. специалистов («спецов»), о которых упомянуто в тексте.
} 
окружающее ее пространство родного урочища, т.е. ландшафт ${ }^{2}$, все объекты которого с малых лет знакомы человеку, а образы этих природных объектов, особенно в случае дальнейшего возможного переезда (фактически отрыва от нутага) формируют в сознании человека образ родины. Возможность перевода слова «нутаг» одновременно как «ландшафт» и как «родина» уже сама по себе говорит о синонимичности этих двух категорий в монгольской языковой картине мира.

Историографически в литературе сложилось понимание нутага как родины/малой родины/кочевья (Бакаева, 2011; Содномпилова, 2007, 2009; Топалова, 2016а, 2016б, 2016в; Bulag, 1998; Kaplonski, 2004). Причем Э. П. Бакаева отмечает, что рассматриваемое понятие «является многозначным и связано не только со значением «кочевье». К примеру, у калмыков XVIII в. данный термин обозначал и все население - «движущийся улус» (Бакаева, 2011: 96, 100). Нутаг - это не только конкретная территория родной местности (Bulag, 1998: 175), но и абстрактно воспринимаемая вся монгольская земля, все государство (Kaplonski, 2004: 184). Таким путем, через понимание нутага соединяются индивидуальные представление о себе, своей семье и малой родине с представлениями обо всем народе, обо всех монголах как сообществе людей, имеющих не только разные родные кочевья, но и общее - всю страну.

Конкретика нутага определяется связью родной территории с духами-хозяевами местности, среди которых могут быть духи-предки конкретного человека, почитающего свой нутаг путем поклонения этим духам (Бакаева, 2016). Монгол-степняк с рождения, с момента закапывания пуповины в родную землю ментально связан с нутагом. Уезжая ему необходимо совершить определенные обряды, связанные с почитанием духов, а возвращаться умирать он должен на свои родные кочевья (Bulag, 1998: 175). Если же человек умер за пределами малой родины, то его тело или пепел (в случае кремации) перевезут на нутаг его родственники.

Когда речь заходит о нутаге, каждый монгол понимает что-то индивидуальное. Во-первых, это понятие, безусловно, ассоциируется с родным местом, но не всегда исключительно с урочищем (если мы беседуем с выходцем из сельской местности). В ряде случаев монгол может начать говорить обобщенно о сомоне или же о целом аймаке, как о своей родине, не концентрируясь на описании природы родного ландшафта, включающего горы, степи и водоемы конкретной родной местности. Во-вторых, если мы говорим о нутаге как о «родных кочевьях», то для родившегося в городе ${ }^{3}$ данный стереотип срабатывает лишь отчасти, поскольку большинство горожан назовут своим нутагом, конечно же не место расположения их родильного дома, а место, где они провели свое детство. В-третьих, часть людей считает своим нутагом место рождения отца, обоих родителей, или же неконкретизированных, обобщенных предков. Данное обстоятельство актуально, например, в отношении западных монголов, родившихся не в традиционных местах расселения (аймаки Ховд и Увс), но считающих своими родными кочевьями сомон своих родителей, а также к горожанам, у которых часто выходцы из сельской местности спрашивают, откуда они приехали? В последнем случае становится крайне важным выявления территориальной идентичности для обозначения пресловутых стереотипно-необходимых границ между «своими» и «чужими». И здесь этническая принадлежность (соотнесение себя с одной из этнической общностей западных монголов или с доминирующими в

\footnotetext{
2 Согласно толковому словарю русского языка Т. Ф. Ефрремовой, ландшафт - это общий вид местности, а местность - это какое-либо определенное пространство на земной поверхности (Ефремова, 2000). В своей кандидатской диссертации я не конкретизировал смысл, вкладываемый в определение слова «ландшафт» и не оговорил свое понимание пространства как многомерного. Дополняя мысль, буду толковать пространство именно как многомерное, т.е. включающее в себя все сферы бытия и небытия, заселенные и охраняемые духами-хозяевами (монг. лус савдаг) данной местности.

3 Преимущественно в столице - Улан-Баторе, который в обыденном понимании считается большинством населения страны единственным городом, несмотря на наличие ряда других населенных пунктов с аналогичным статусом (например, гг. Дархан и Эрдэнэт).
} 
стране халха-монголами) играет самую незначительную роль. В других случаях акцент интеракции смещается именно на межэтнический аспект, в котором иногда больным местом выступают аудиально-фонетические различия между основным монгольским говором и ойратским (западномонгольским) диалектом.

Как мы видим, на вопрос «Где находится Ваш нутаг?» не всегда можно получить ответ именно о месте фактического рождения, что является точным выражением сложности этого понятия. Отторжение города как нутага идет и самим горожанином и внешним актором, родившимся в сельской местности, провоцирующим своего собеседника уточняющим вопросом о месте рождения родителей. Таким образом, представление о нутаге - это необходимая и неотделимая часть самоидентификации современного монгола. В этом контексте престижная городская идентичность, ставшая таковой в наши дни не только среди молодежи, обнуляется. Своеобразный кризис идентичности у городского монгола может основываться на отсутствии связи с реальным родным ландшафтом, с природой родного края - локальным семейным пространством и духами-хозяевами местности, являющимися его частью. Горожанин в качестве нутага назовет чаще всего определенную локацию (преимущественно, аймак, если собеседник не будет углубляться в тему с вопросами о сомоне и конкретном урочище), не заостряя внимание на природе родного края. Здесь уже проявляется дистанцирование монгола от духов-хозяев местности и/или духов предков, местообитание которых обычно связывают с объектами родной природы.

Источники изучения нутага можно предельно условно поделить на три группы: устные, старописьменные и современные музыкально-литературные. К первой группе относятся вся информация, которую можно получить в процессе наблюдения, опроса и интервьюирования. Меня, в первую очередь, интересует живое восприятие нутага современными монголами, рефлексии людей в отношении родных кочевий, роль родных кочевий в формировании и презентации этничности и функционирование образа родина в современной этнической культуре Монголии.

Также к этой группе можно отнести устные фольклорные источники, правда, в течение $\mathrm{XX}$ в. довольно подробно изученные и записанные. Речь идет о народных протяжных песняхвосхвалениях (монг. магтаал). Для примера рассмотрим некоторые тексты, посвященные горам Хангая и народную песню «Два алтайских нутука» (Топалова, 2016а, 2016б, 2016в).

Вторая группа источников включает преимущественно буддийские старописьменные (т.е. зафиксированные на старомонгольской письменности монгол бичиг) памятники - гимнывоскурения духам-хозяевам местности. Эта группа включает такие тексты, как «гимн нутуку торгутов» (Бакаева, 2011), «сутра о ниспослании дождя и жертвоприношении духам-хозяевам кочевий джунгарских дербетов» (Орлова, 2015), «воскурение нутуку дербетов» (Орлова, 2016) $)^{4}$ и мн. др.

Данные источники представляют собой тексты поклонения духам-хозяевам или духампокровителям кочевий, совершаемые через жертвоприношение-воскурение ключевым почитаемым местными дербетами природным объектам, расположенным в Западной Монголии: горам, озерам, рекам, родникам-аршанам. Причем эти источники, имеющие шаманское происхождение, записаны в буддийской литературной традиции и имеют соответствующие религиозно-стилевые формулировки: принятие трех драгоценностей (Будда, дхарма, сангха), использование мантр и т.д.

В них видно конкретное, можно сказать, «классическое» понимание нутага как природного ландшафта. Важность природного фактора в этнической культуре монголов, начиная с самого рождения, не вызывает никакого сомнения. Общеизвестно, что образ жизни монголакочевника неразрывно связан с природным окружением, а его микромир расширяется за счет природных объектов родного урочища, в центре которого находится юрта - сакрализованная

\footnotetext{
4 Не ставя задачу перечисления всех возможных старописьменных источников, ограничимся упомянутыми, что вполне достаточно для презентации источниковой базы.
} 
модель вселенной (Жуковская, 1988: 14-16). Путем сакрализации видимого пространства, установления и поддерживания через воскурения связи с духами-хозяевами местности происходит попытка одомашнивания невидимого пространства.

В подтверждение этнографического материала приведем социологические данные новосибирского исследователя Д. В. Ушакова. Взрослые респонденты из западных монголов среди факторов, влияющих на этническое самоопределение, на первое место ставят «территорию проживания моего народа» (подростки этому отводят второе место). У практически 57\% опрошенных взрослых «природа моего края» относится к обстоятельствам, повлиявших на этническую идентификацию. Также среди сельской молодежи Западной Монголии на вопрос «Насколько в жизни для тебя важно следующее?» (предусматривает возможность выбора нескольких ответов) многие сразу же после выбора «хорошего образования» $(9,6 \%$ ответивших) выделяют патриотические чувства: «любить Монголию» (9,5\%), «любить регион (аймак) своего проживания» $(9,1 \%)$, «знать язык своего народа» $(8,9 \%)$, «жить в своей стране» $(7,9 \%)$ (Кимеев и др., 2013: 44-45, 54). Это только подтверждает значимость нутага.

Третья группа источников изучения нутага - литературные и музыкальные произведения авторов XX - нач. XXI в. Здесь образцом для понимания смысла, вкладываемого каждым монголом в слово «нутаг», может служить стихотворение (или, по определению филолога Л. Г. Скородумовой, «поэма» (Скородумова, 2007: 23)) основоположника современной монгольской литературы Д. Нацагдоржа «Миний нутаг», неоднократно переведенное на русский язык. В каждом из вариантов интересующее нас слово переводилось как «родина».

По моему мнению, основанном на многолетних наблюдениях, монголы особо выделяют «Миний нутаг» из всех стихотворений, написанных на родном языке. В 4-5-х классах его учат наизусть в школе ${ }^{5}$, оно стоит на первом месте в списке 10 стихотворений, которые, по мнению журналистов, обязана знать современная молодежь (Ганчимэг, 2015). Стихотворение «отражает мифопоэтические представления древних монголов о вселенной» (Скородумова, 2007: $23)$ и воплощает патриотические чувства современных монголов.

Д. Нацагдорж описывает нутаг в разных плоскостях, сдвигаясь от общего к частному: от территории всей Монголии, которая ассоциируется с космосом, всем миром, до обжитого локального пространства - индивидуальной родной местности - отдельного монгола, до пространства, где «мы хоронили предков», где «дети множились и росли» (Скородумова, 2016: 105, 108). Ключевые образы-объекты, составляющие территорию страны - это горные хребты (Хэнтэй, Хангай, Саяны), озера (Хубсугул, Увс, Буйр), реки (Орхон, Селенга, Хөхийн голб), степи, ручьи, родники. Поэт начинает свое повествование, очерчивая северные горные и южные пустынные границы Монголии. Причем он не замыкается исключительно в пространственной характеристике территории, а дает временную ретроспективу, хронологически отодвигая границы нутага до периода господства хунну (III-II вв. до н.э.).

По мнению литературоведов, «Миний нутаг» продолжает традицию шаманских гимнов и хвалебных песен. Это видно в ритме, технике стихосложения и, безусловно, в самой семантике образов, их символике и содержании стихотворения - «воспевании сакральных природных объектов», об этом говорил и сам автор (Дампилова, 2007: 33; Скородумова, 2007: 25).

\footnotetext{
5 Некоторые собеседники отмечают, что в отличие от них не все образы Д. Нацагдоржа понятны их 10-летним детям. Например, современные школьники не сразу представляют местоположение географических объектов, описываемых поэтом, и, соответственно, не всегда понимают, о чем именно идет речь. Сейчас на уроках монгольской литературы в процессе анализа данного произведения происходит знакомство учащихся с географией родной страны.

${ }^{6}$ Определение местоположения данной реки в Монголии вызвало некоторые затруднения. По мнению монгольского историка и журналиста Г. Турмунха, река Хөхийн гол находится неподалеку от северной оконечности нутага самого Д. Нацагдоржа (урочище Гун галуутай - современный сомон Баяндэлгэр Центрального аймака). Таким образом, автор представляет свои родные кочевья, вплетенными в пространство всей страны.
} 
Д. Нацагдорж выразил поэтический образ нутага, из которого черпают вдохновение многие современные исполнители и поэты. Предположим, что образы, сформулированные поэтом в «Миний нутаг», как впитанные монголами со школьной скамьи, подсознательно влияют на тексты современных авторов. Характерной чертой современных исполнителей и авторов текстов песен является переход на уровень аймака или неопределенного «родного края», под которым опять же подразумевается аймак. Его собирательный образ презентуется через воспевание природы: максимально известных и брендированных ландшафтных объектов. Подобной брендизацией занимаются аймачные землячества, которые в столице публикуют издания энциклопедического или справочного характера о родном аймаке, но чаще всего фотоальбомы, основное содержание которых - это изображения природных объектов родного края. Конечно, это было бы невозможно без финансирования, оказываемого бизнесменами-выходцами из той или иной провинции.

Трансляция образа нутага на весь аймак в последнее время становится актуальной не только в контексте организации землячеств, но и в контексте сопоставления разных аймаков в своеобразной соревновательной манере, что напоминает древнегреческую агональность. Вероятнее всего, закрепление в массовом сознании соотношения каждого аймака с какими-то только ему присущими качествами (например, специфическим этническим составом) произошло при социализме, когда была окончательно оформлена современная административно-территориальная система деления страны. Тогда же установилась связь различных форм прозвищного фольклора с конкретным аймаком.

В некоторых примерах современного монгольского музыкально-вокального творчества образ нутага становится предельно отвлеченным, без обозначения конкретных ландшафтных объектов, как, например, в песнях «Очертания родных кочевий» ${ }^{7}$ и «Силуэт моей родины» ${ }^{8}$. Данная абстрактность образа подчеркивается главным словом названия (монг. бараа), переводимым как «очертания, силуэт, контуры». В данных песнях отсутствуют конкретные топонимы и употребляются традиционные для данного вида творчества образы и мотивы. Так, в первой песне вечноснежные горы сопоставляются с матерью, а сама природа, весь родной край встречает человека, возвращающегося домой, раньше родной мамы, выходящей из юрты. Во второй - родные кочевья «украшены стадами пасущегося скота», здесь находится материнская белая юрта, навечно остаются следы от кропления молока, а синие горы прижимаются к небу, по которому бегут белые облака.

В видеоклипах, снятых на данные песни, демонстрируются не только различные виды флоры, но и представители монгольской фауны, создающие динамичную картину. Судя по комментариям к данным произведениям, оставленным под видео, большинству слушателей строки песен без труда навеивают мысли о своем индивидуальном локальном нутаге, что говорит об универсальности образов, представляемых в современных композициях. Аналогичных песен, в той или иной мере касающиеся данной тематики, существует несколько десятков.

Образность, лирика и метафоры современных сочинений, а также ассоциации со словом «нутаг», вплетенные в поэтику сегодняшних популярных песен ряды, являются традиционными и стандартных для монгольских текстов воскурений-гимнов. К слову сказать, и тема разделенности с родиной - это один из типичных сюжетов как народных лирических песен, так и современных авторских. Для примера приведу цитату из протяжных монгольских песен, посвященных Хангаю: «Южный Хангай видится издалека любимым... Западный Хангай видится красивым издалека» (Топалова, 2016б: 81-82).

\footnotetext{
7 Бурмаа Л., Мөнхбат Д. \& Банзрагч А. Төрсөн нутгийн бараa // YouTube. 22.01.2015. URL: https:// www.youtube.com/watch?v= pl5wWqxB_Tg (дата обращения 08.01.2018).

${ }^{8}$ Найдандорж. Миний нутгийн бараa // YouTube. 16.12.2015. URL: https://www.youtube.com/watch?v=PvHuw7jBq4Q (дата обращения 08.01.2018).
} 
Еще одним важным современным текстом из разряда третьей группы источников является произведение Халуун элгэн нутаг (монг. «Горячие родные кочевья»). Песня, написанная на стихи монгольского поэта, заслуженного деятеля искусств Ж. Бадраа, в 1971 г. была удостоена государственной премии. По результатам опроса газеты Зууны мэдээ она признана лучшей композицией XX в. В песне отмечаются важные признаки-образы родины: колыбель, отец и мать, реки и горы, ветер, ласкающий лицо и освещающий душу. Композиция стала гимном не только монголов, но и калмыков, бурят и внутренних монголов КНР, она считается неофициальным, вторым гимном страны. В центре Улан-Батора данной песне установлен памятник.

Итак, затронутая тема вряд ли может быть полноценно раскрыта в рамках статьи. Она требует досконального изучения, причем с учетом обширности монгольской территории и соответствующей локальной этнической специфики осознания и проекции образа нутага. Из всего вышеизложенного, представляющего уникальные для всех монголов сюжеты, можно сделать следующие обобщающие выводы.

Во-первых, представление о нутаге является базовым для самоидентификации монгола любой этнической общности. Данная идентичность по территориальному признаку, возможно, престижнее и, в некоторых случаях, важнее родовой, этнической и городской.

Во-вторых, охарактеризовав определенный в статье круг источников, можно констатировать, что поэтический образ нутага был сформулирован одним из основоположников современной монгольской литературы Д. Нацагдоржем, создавшим лирическую форму изображения малой родины в своем стихотворении «Миний нутаг». Происхождение этой формы связывается с воскурениями духам-хозяевам местности, убрав из которых все религиозные коннотации, можно получить тексты, похожие как на классический «Миний нутаг», так и на тексты современных песен, посвященных родине. Современные авторы, с детства впитывавшие элементы творчества Д. Нацагдоржа, неосознанно используют его форму, наполняя ее своим индивидуальным содержанием. Таким образом, современные сочинения являются наследниками гимнов, обращенных к духам-хозяевам местности. Мы видим, как изменившееся содержание сохранило общую форму: и сегодня монгольского автора, в первую очередь, влекут природные объекты родного ландшафта.

В-третьих, случай с нутагом - это пример перехода маркеров этничности в плоскость сознания и становления их имплицитными, отличными от внешних проявлений материальной культуры. Значимость нутага определяется необходимостью обретения идентичности, особенно в условиях проживания в Улан-Баторе тех монголов, которые еще недавно были кочевыми скотоводами. В такой ситуации отрыва от родных кочевий образы малой родины становятся максимально актуальными, что находит свое отражение в создании в столице землячеств, брендизации локально-обобщенного нутага - аймака, частичной мифологизации и ностальгии.

В-четвертых, индивидуальность восприятия и понимания нутага имеет свою специфику, которая становится ясна из контекста и играет главную роль в процессе самоидентификации, например, во время беседы нескольких монголов, родившихся в разных местностях и встретившихся на «нейтральной территории». Обычно обобщенное представление о нутаге укладывается в границы аймака. Этого становится достаточно для удовлетворения интереса большинства собеседников. Тем не менее, каждый монгол по отдельности под словом «нутаг» будет понимать что-то свое личностное, ассоциирующееся с очертаниями определенных природных объектов, чаще всего - горы, пусть даже и не всегда расположенной в конкретном родном ландшафте этого человека, но почитаемой в его регионе или на государственном уровне и особенно известной среди всех монголов.

В-пятых, дальнейшее расширение исследования нутага потребует применения эмного подхода (еmic-анализа), который подразумевает изучение монгольской идентичности с точки зрения самих монголов путем использования «терминов носителей данной культуры и специфичных для культуры единиц анализа» (Иванова, Почебут, 2013: 89). Данный подход использовался мной по ходу написания статьи, когда приходилось употреблять термин «нутаг» как 
прямое заимствование из монгольского, поскольку смысловая насыщенность и индивидуальность восприятия его ускользает при переводе на русский язык.

Как видно, представление о нутаге - традиционно конкретном ландшафте, населенном хозяевами местности и/или духами предков реальных людей, поддерживающих психоэмоциональную, ментальную связь со своими родными кочевьями, сегодня подменяется обобщенными образами и становится абстракцией эксплицитно лишь для стороннего наблюдателя. По сути нутаг, по-прежнему, для каждого монгола сохраняет глубинную, не проявляемую вовне смысловую нагрузку.

\section{Список литературы}

Бакаева Э. П. «Нутук»: к вопросу о понятии «кочевье» и территории расселения ойратов (на материалах фольклора) // Монголоведение. - 2011. - № 5. - С. 96-108.

Бакаева Э. П. Отзыв официального оппонента на диссертацию В. И. Терентьева. - 2016. URL: http://www.tsu.ru/science/disadvice/announcement_1_of_the_dissertations_in_the_tsu_avtors.php

Большой академический монгольско-русский словарь: В 4 т / отв. ред. Г. Ц. Пюрбеев. - М.: Academia, 2001-2002.

Дампилова Л. С. Д. Нацагдорж и современная монголоязычная поэзия // Mongolica-VII. - СПб.: Петербургское Востоковедение, 2007. - С. 32-34.

Ефремова Т. Ф. Толковый словарь русского языка. Толково-словообразовательный. - М.: Русский язык, 2000. URL: https://www.efremova.info/word/landshaft.html\#.Wk2oFtJI_IU (дата обращения 08.01.2018).

Жуковская Н. Л. Категории и символика традиционной культуры монголов. - М.: Наука, 1988. - 194 с.

Иванова И. Н., Почебут Л. Г. Динамика шведской этничности // Музей. Традиции. Этничность. - 2013. - № 2 (4). C. 88-98.

Кимеев В. М., Акулова А. С., Ушаков Д. В., Терентьев В. И., Батсуурь Лхагвасурэн. Очерки Западной Монголии. Т. 2. Этнокультурные взаимодействия народов Западной Монголии и российского Саяно-Алтая. - Кемерово: Офсет, 2013. - 199 c.

Орлова К. В. К исследованию этнических маркеров дербетов Монголии: текст воскурения «духам-хозяевам» кочевий // Проблемы этнической истории и культуры тюрко-монгольских народов. - Вып. 3. - Элиста: КИГИ РАН, 2015. - C. 79-95.

Орлова К. В. Воскурение нутуку дербетов Монголии // Восток (Oriens). - 2016. - № 6. - С. 132-141.

Скородумова Л. Г. Мифопоэтическая концепция в творчестве Д. Нацагдоржа (Опыт реконструкции текста) // Mongolica-VII. - СПб.: Петербургское Востоковедение, 2007. - С. 23-31.

Скородумова Л. Г. Монгольская литература XIX-XX веков. Вопросы поэтики. - М.: РГГУ, 2016. - 311 с.

Содномпилова М. М. Концепт Родина в культуре монгольских народов // Этнографическое обозрение. - 2007. № 3. - C. 124-134.

Содномпилова М. М. Мир в традиционном мировоззрении и практической деятельности монгольских народов. Улан-Удэ: Изд-во БНЦ СО РАН, 2009. - 366 с.

Топалова Д. Ю. Образ «нутг» в лирике Осорин Утнасн (на примере стихотворения «Нутгтан нерәдсн седкл») // Проблемы этнической истории и культуры тюрко-монгольских народов. - Вып. 4. - Элиста: КалмНЦ РАН, 2016а. C. $112-129$.

Топалова Д. Ю. Образ Хангая в народных лирических песнях Монголии // Проблемы этнической истории и культуры тюрко-монгольских народов. - Вып. 4. - Элиста: КалмНЦ РАН, 2016б. - С. 77-91.

Топалова Д. Ю. О дербетской народной песне «Два алтайских нутука» // Проблемы этнической истории и культуры тюрко-монгольских народов. - Вып. 4. - Элиста: КалмНЦ РАН, 2016в. - С. 92-101.

Bulag U. E. Nationalism and hybridity in Mongolia. - New York: Oxford University Press, 1998. - 302 p.

Kaplonski C. Truth, history and politics in Mongolia. The memory of heroes. - London \& New York: RoutledgeCurzon, 2004. $-248 \mathrm{p}$.

Терентьев В. И., кандидат исторических наук, учитель истории.

Улан-Баторский филиал РЭУ им. Г. В. Плеханова.

Пр. Мира, 131, Улан-Батор, Монголия, 210351.

E-mail: vlad33@bk.ru 


\section{Terentyev V. I.}

\section{«NUTAG» AS UNDERSTANDING OF THE IMAGE OF A SMALL MOTHERLAND OF MODERN MONGOLIANS}

An important component of the contemporary Mongolian ethnicity - native nomadic places («nutag») and their representations are being explored. Different variations of the interpretation of this image are given. The situational essence of nutag perception is analyzed. Particular attention is paid to individual features of understanding and localization of a small homeland. The sources of the nutag study are conditionally divided into three groups: oral, old-written and modern musical-literary. When considering sources, special attention is paid to the literary and musical-poetic creativity of Mongolian authors of the $20^{\text {th }}$ - early $21^{\text {st }}$ century. The traditional notion of nutag is an understanding of the specific landscape in which the spirit-masters and the spirits of the ancestors of living people inhabit. These people support a psycho-emotional and mental connection with their native nomadic places. Today this representation is replaced by generalized images and only for an outside observer it becomes an abstraction. In fact, the nutag, as before, for each Mongolian retains a deep semantic load that is not extrapolated to the outside observers. In conclusion, the dual essence of the contemporary ideas about the Mongol homeland is emphasized: external abstractness and internal individual imagery, which is associated with a specific locality, natural objects and spirits-masters of the native landscape.

Key words: Mongolia, Mongolians, ethnic self-consciousness, ethnicity, homeland, image.

\section{References:}

Bakaeva Je. P. «Nutuk»: k voprosu o ponjatii «kochev'e» i territorii rasselenija ojratov (na materialah fol'klora) [«Nutuk»: towards the concept «kochev'e» and the territory of settlement of Ojrats (based on folklore)] // Mongolovedenie. - 2011. № 5. - S. 96-108. (in Russian)

Bakaeva Je. P. Review by the formal opponent of the dissertation by V. I. Terent'ev: - 2016. - URL: http://www.tsu.ru/science/disadvice/announcement_1_of_the_dissertations_in_the_tsu_avtors.php (in Russian)

Bol'shoj akademicheskij mongol'sko-russkij slovar': V 4 t. [Big academic Mongol-Russian dictionary] / Otv. red. G. C. Pjurbeev. - M.: Academia, 2001-2002. (in Russian)

Dampilova L. S. D. Nacagdorzh i sovremennaja mongolojazychnaja pojezija [Nacagdorzh and modern Mongol language poetry] // Mongolica-VII. - SPb: Peterburgskoe Vostokovedenie, 2007. - P. 32-34. (in Russian)

Efremova T. F. Tolkovyj slovar' russkogo jazyka. Tolkovo-slovoobrazovatel'nyj. [Thesaurus of Russian language] - M.: Russkij jazyk, 2000. - URL: https://www.efremova.info/word/landshaft.htmI\#.Wk2oFtJIIU (data obrashhenija 08.01.2018). (in Russian)

Zhukovskaja N. L. Kategorii i simvolika tradicionnoj kul'tury mongolov. [Categories and symbolism of traditional Mongolian culture] - M.: Nauka, 1988. - 194 p. (in Russian)

Ivanova I. N., Pochebut L. G. Dinamika shvedskoj jetnichnosti [Dynamics of Swedish ethnos] // Muzej. Tradicii. Jetnichnost'. - 2013. - № 2 (4). - P. 88-98. (in Russian)

Kimeev V. M., Akulova A. S., Ushakov D. V., Terent'ev V. I., Batsuur' Lhagvasurjen. Ocherki Zapadnoj Mongolii. [Survey of Western Mongolia]. - T. 2. Jetnokul'turnye vzaimodejstvija narodov Zapadnoj Mongolii i rossijskogo Sajano-Altaja. Kemerovo: Ofset, 2013. - 199 p. (in Russian)

Orlova K. V. K issledovaniju jetnicheskih markerov derbetov Mongolii: tekst voskurenija «duham-hozjaevam» kochevij [Towards the study of ethnic markers of Mongol Derbets: resurrection of "patron spirits" texts] // Problemy jetnicheskoj istorii i kul'tury tjurko-mongol'skih narodov. - Vyp. 3. - Jelista: KIGI RAN, 2015. - P. 79-95. (in Russian)

Orlova K. V. Voskurenie nutuku derbetov Mongolii [The ceremony of nutuk smoking in Mongol Derbets] // Vostok (Oriens). - 2016. - № 6. - P. 132-141. (in Russian)

Skorodumova L. G. Mifopojeticheskaja koncepcija v tvorchestve D. Nacagdorzha (Opyt rekonstrukcii teksta) // MongolicaVII. - SPb.: Peterburgskoe Vostokovedenie, 2007. - P. 23-31. (in Russian)

Skorodumova L. G. Mongol'skaja literatura XIX-XX vekov. [Mongol literature of $19^{\text {th }}-20^{\text {th }}$ C.]. - Voprosy pojetiki. - M.: RGGU, 2016. - 311 p. (in Russian)

Sodnompilova M. M. Koncept Rodina v kul'ture mongol'skih narodov [The concept of Motherland in Mongol culture] // Jetnograficheskoe obozrenie. - 2007. - № 3. - P. 124-134. (in Russian) 
Sodnompilova M. M. Mir v tradicionnom mirovozzrenii i prakticheskoj dejatel'nosti mongol'skih narodov. [The world in traditional outlook and practical activities of Mongol people]. - Ulan-Udje: Izd-vo BNC SO RAN, 2009. - 366 p. (in Russian) Topalova D. Ju. Obraz «nutg» v lirike Osorin Utnasn (na primere stihotvorenija «Nutgtan nerədsn sedkl») [The image of «nutg»] in Osorin Utnasn lyrics (exemplified by the poem «Nutgan neredsn sedkl») // Problemy jetnicheskoj istorii i kul'tury tjurko-mongol'skih narodov. - Vyp. 4. - Jelista: KalmNC RAN, 2016a. - P. 112-129. (in Russian)

Topalova D. Ju. Obraz Hangaja v narodnyh liricheskih pesnjah Mongolii [The image of Khangaj in Mongol folk lyrical songs] // Problemy jetnicheskoj istorii i kul'tury tjurko-mongol'skih narodov. - Vyp. 4. - Jelista: KalmNC RAN, 2016b. - P. 77-91. (in Russian)

Topalova D. Ju. O derbetskoj narodnoj pesne «Dva altajskih nutuka» [On Derbet folk songs] // Problemy jetnicheskoj istorii i kul'tury tjurko-mongol'skih narodov. - Vyp. 4. - Jelista: KalmNC RAN, 2016c. - P. 92-101. (in Russian)

Bulag U. E. Nationalism and hybridity in Mongolia. - NewYork: Oxford University Press, 1998. - 302 p.

Kaplonski C. 2004. Truth, history and politics in Mongolia. The memory of heroes. - London; New York: RoutledgeCurzon, 2004. $-248 \mathrm{p}$.

Terentyev V. I., PhD in history, history teacher.

Plekhanov Russian University of Economics, Ulaanbaatar branch.

Peace avenue, 131, Ulaanbaatar, Mongolia, 210351.

E-mail: vlad33@bk.ru 